\title{
Reimplantation versus remodeling in valve-sparing surgery for aortic root aneurysms: a meta-analysis
}

\author{
Zhuoming Zhou ${ }^{1,2 \#}$, Mengya Liang ${ }^{1,2 \#}$, Suiqing Huang ${ }^{1,2}$, Zhongkai $\mathrm{Wu}^{1,2}$ \\ ${ }^{1}$ Department of Cardiac Surgery, First Affiliated Hospital of Sun Yat-sen University, Guangzhou, China; ${ }^{2}$ NHC Key Laboratory of Assisted \\ Circulation, Sun Yat-sen University, Guangzhou, China \\ Contributions: (I) Conception and design: M Liang, Z Zhou; (II) Administrative support: Z Wu; (III) Provision of study materials or patients: M \\ Liang, Z Wu; (IV) Collection and assembly of data: Z Zhou, S Huang; (V) Data analysis and interpretation: Z Zhou, S Huang; (VI) Manuscript \\ writing: All authors; (VII) Final approval of manuscript: All authors. \\ \#These authors contributed equally to this work. \\ Correspondence to: Zhongkai Wu, MD, PhD. Department of Cardiac Surgery, First Affiliated Hospital of Sun Yat-sen University, 58 Zhongshan II \\ Road, Guangzhou 510080, China. Email: wuzhk@mail.sysu.edu.cn.
}

Background: Valve-sparing aortic root replacement (VSARR), which includes reimplantation and remodeling techniques, has been developed as an important treatment for aortic root aneurysms. We aimed to evaluate the outcomes of reimplantation versus remodeling techniques in valve-sparing surgery for aortic root aneurysms.

Methods: A systematic review and meta-analysis was performed by searching PubMed, Embase and the Cochrane Library until November 2019. Fourteen retrospective cohort studies comparing reimplantation with remodeling techniques for aortic root aneurysms were included and contained at least one of the following outcomes: early mortality, late mortality, aortic valve-related reoperation, and postoperative moderate to severe aortic regurgitation (AR).

Results: The outcomes of 1,672 patients (1,011 underwent reimplantation surgery, and 661 underwent remodeling) were analyzed. Compared with remodeling, the reimplantation technique was associated with a significantly lower risk of late mortality $\left(\mathrm{RR}=0.34 ; 95 \% \mathrm{CI}, 0.17-0.71 ; \mathrm{P}=0.004 ; \mathrm{I}^{2}=37 \%\right)$ and reoperation $\left(\mathrm{RR}=0.31 ; 95 \% \mathrm{CI}, 0.12-0.76 ; \mathrm{P}=0.01 ; \mathrm{I}^{2}=55 \%\right)$. There was no significant difference in early mortality $\left(\mathrm{RR}=0.69 ; 95 \% \mathrm{CI}, 0.31-1.53 ; \mathrm{P}=0.36 ; \mathrm{I}^{2}=0 \%\right)$, postoperative moderate to severe $\mathrm{AR}(\mathrm{RR}=0.64 ; 95 \% \mathrm{CI}$, $\left.0.31-1.32 ; \mathrm{P}=0.22 ; \mathrm{I}^{2}=36 \%\right)$ or postoperative stroke $\left(\mathrm{RR}=1.26 ; 95 \% \mathrm{CI}, 0.58-2.75 ; \mathrm{P}=0.56 ; \mathrm{I}^{2}=0 \%\right)$ between the two groups. No evidence of publication bias was detected.

Conclusions: The current meta-analysis indicate that patients who undergo reimplantation procedures have a significantly lower risk of late mortality and reoperation than those who undergo remodeling procedures. Early mortality, postoperative moderate to severe AR and stroke were comparable between the two techniques.

Keywords: Aortic root aneurysm; valve-sparing; reimplantation; remodeling

Submitted Mar 20, 2020. Accepted for publication Jul 29, 2020.

doi: $10.21037 /$ jtd-20-1407

View this article at: http://dx.doi.org/10.21037/jtd-20-1407 


\section{Introduction}

The surgical treatment for patients with aortic root aneurysms is still under debate. In the past, standard composite aortic root replacement (Bentall and De Bono procedure) has been regarded as the first choice in the surgical treatment of aortic root aneurysms $(1,2)$. In recent decades, valve-sparing aortic root replacement (VSARR), including reimplantation and remodeling techniques as well as their modifications (3-5), which can preserve native aortic valves and alleviate the risk of lifelong anticoagulationrelated hemorrhagic complications and mechanical valverelated thromboembolism, has been developed for these patients. It should be noted that in recent years, VSARR has been performed in various heart centers, with an increasing number of surgeons opting to perform VSARR rather than composite aortic root replacement (6-9).

Reimplantation techniques were first introduced by David in 1992 (10) and remodeling by Yacoub in 1983 (11). Reimplantation techniques can successfully reduce annular dilatation and stabilize the basal ring and sinotubular junction; however, these techniques fail to restore the sinus of Valsalva $(3,12)$, which enables the aortic annulus to move physiologically during the cardiac cycle. By contrast, although the remodeling technique is able to reconstruct the sinus of Valsalva, postoperative dilation of the ventriculo-aortic junction may possibly result in a relatively high failure rate $(13,14)$. Schematic diagram illustrating the reimplantation and the remodeling techniques was shown in Figure 1.

Currently, there is still no consensus on which VSARR technique is superior in terms of long-term postoperative outcomes. The results of several previously published systematic reviews and meta-analyses remain controversial due to small populations and short follow-up periods (15-17). Recently, some retrospective cohort studies with larger populations and longer follow-up periods have been published and have provided new evidence for further analysis (18-21).

To further investigate the long-term outcomes of reimplantation and remodeling procedures in patients with aortic root aneurysms, we included an update of the currently published data and performed a systematic review and meta-analysis focused on early mortality, late mortality, reoperation rate, postoperative moderate to severe aortic regurgitation (AR) and stroke during follow-up.

We present the following article in accordance with the PRISMA reporting checklist (available at http://dx.doi. org/10.21037/jtd-20-1407).

\section{Methods}

\section{Search strategy}

Our meta-analysis was reported based on the Preferred Reporting Items for Systematic reviews and Meta-Analyses (PRISMA) and has been registered at International prospective register of systematic reviews (PROSPERO, number CRD42020159743). We performed a systematic search of major databases, including PubMed, Embase and the Cochrane library, by using keywords and medical subject heading (Mesh) that included the following words: (aorta OR aortic valve OR aortic aneurysm OR aortic root OR aortic dissection OR Marfan) AND (reimplantation OR remodeling OR valve sparing OR valve preserving OR David OR Yacoub). Additional articles from the reference lists of eligible studies that met the inclusion criteria were also included.

\section{Selection criteria}

All retrospective cohort studies comparing reimplantation with remodeling techniques for VSARR in patients with aortic root aneurysms, with or without dissection or Marfan syndrome, and containing at least one of the following outcomes were included: early mortality ( $<30$ days or inhospital), late mortality, reoperation (valve-related or aortarelated) rate, and postoperative moderate to severe aortic AR (including residual or recurrence). The exclusion criteria were as follows: follow-up less than one year, mean age younger than 18 years old, reviews, conference abstracts, case reports and letters. The quality of the included studies was assessed based on the Newcastle-Ottawa Scale (NOS) checklist of cohort studies, and a quality score was assigned for each study.

\section{Data extraction}

The selection and assessment of studies as well as data extraction were completed by two review authors (ZZM and HSQ) independently. Calibration was performed, and discrepancies between the two authors were discussed until they reached a consensus. A third review author (LMY) participated in the discussion when necessary. The following information from each study was extracted as completely as possible: authors, year, country, operative period, number of patients in each group, duration of follow-up, age, sex, cardiopulmonary bypass (CPB) time, aortic clamping time, early mortality, late mortality, 
A

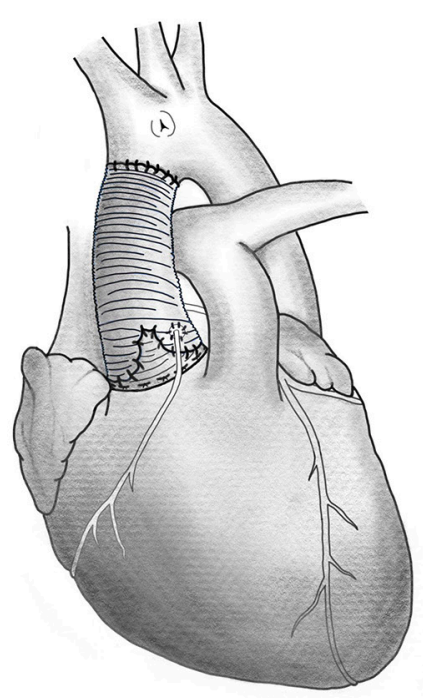

B

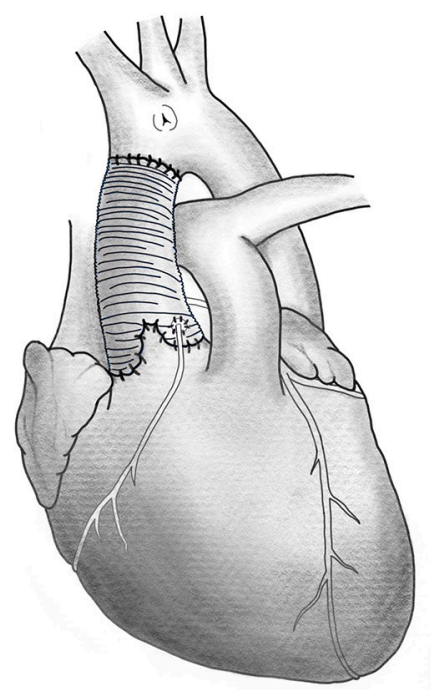

Figure 1 Schematic diagram illustrating (A) the reimplantation and (B) remodeling techniques.

reoperation rate, postoperative moderate to severe $\mathrm{AR}$ and stroke. The latest studies with the most complete data were selected with priority if several publications came from the same population.

\section{Strategy for data synthesis}

All analyses were performed in RevMan 5.3 software or STATA 15.0 software. Statistics were calculated as RRs with 95\% CIs and $\mathrm{P}$ values (considered statistically significant when $\mathrm{P}<0.05)$ for dichotomous variables including mortality, reoperation rate, postoperative $\mathrm{AR}$, postoperative stroke and mean difference \pm standard deviation $(M D \pm S D)$ for continuous variables including the CPB time and aortic clamping time. Subgroup analysis of Marfan syndrome and acute type A dissection was performed in studies of patients with specific etiology. The results were presented with forest plots. The heterogeneity between studies was evaluated with the Cochran $\mathrm{Q}$ test and the calculation of the $\mathrm{I}^{2}$ statistic (P value less than 0.1 or $\mathrm{I}^{2}$ greater than $50 \%$ indicated substantial heterogeneity). Publication bias was assessed with Egger's test.

\section{Results}

\section{Study characteristics}

A total of 1,588 studies were identified through database searches, and 14 retrospective cohort studies published between 1998 and 2018 were finally included (Figure 2) (18,19,21-28,29-32). The NOS scores of the studies were all above 5 , and no study was excluded due to poor quality. The baseline characteristics and NOS scores of all included studies are summarized in Tables 1,2. A total of 1,672 patients were included, among whom 1,011 underwent reimplantation surgery, and 661 underwent remodeling surgery. The mean number of follow-up years ranged from $1.5 \pm 0.7$ years (22) to $8.9 \pm 5.2$ years (19).

\section{Publication bias}

No evidence of publication bias was detected with Egger's test.

\section{Analysis results}

\section{CPB time and aortic clamping time}

The results of the CPB time and aortic clamping time are shown in Figure $3 A, B$. Six studies $(18,19,21,23,25,31)$ were included in the analysis of CPB time (1,045 patients: 702 with reimplantation and 343 with remodeling) and aortic clamping time (1,045 patients: 702 with reimplantation and 343 with remodeling). The results indicated that a longer CPB time (random effects model, mean difference $=20.31$; 95\% CI, 9.40-31.22; $\mathrm{P}=0.0003)$ and aortic clamping time (random effects model, mean difference $=25.90 ; 95 \% \mathrm{CI}$, 13.73-38.07; $\mathrm{P}<0.0001$ ) were observed in the reimplantation group, as expected previously. However, the Cochran Q 


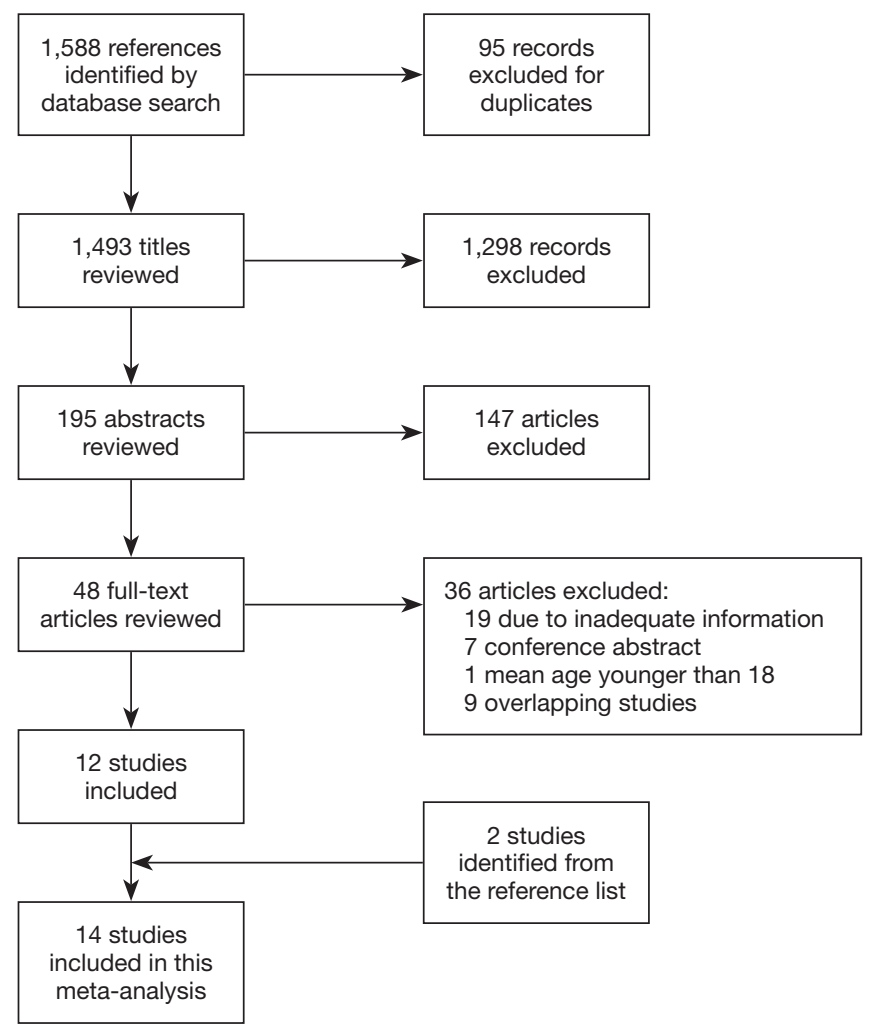

Figure 2 Flow chart of study inclusion.

Table 1 Main characteristics and NOS scores of the included studies

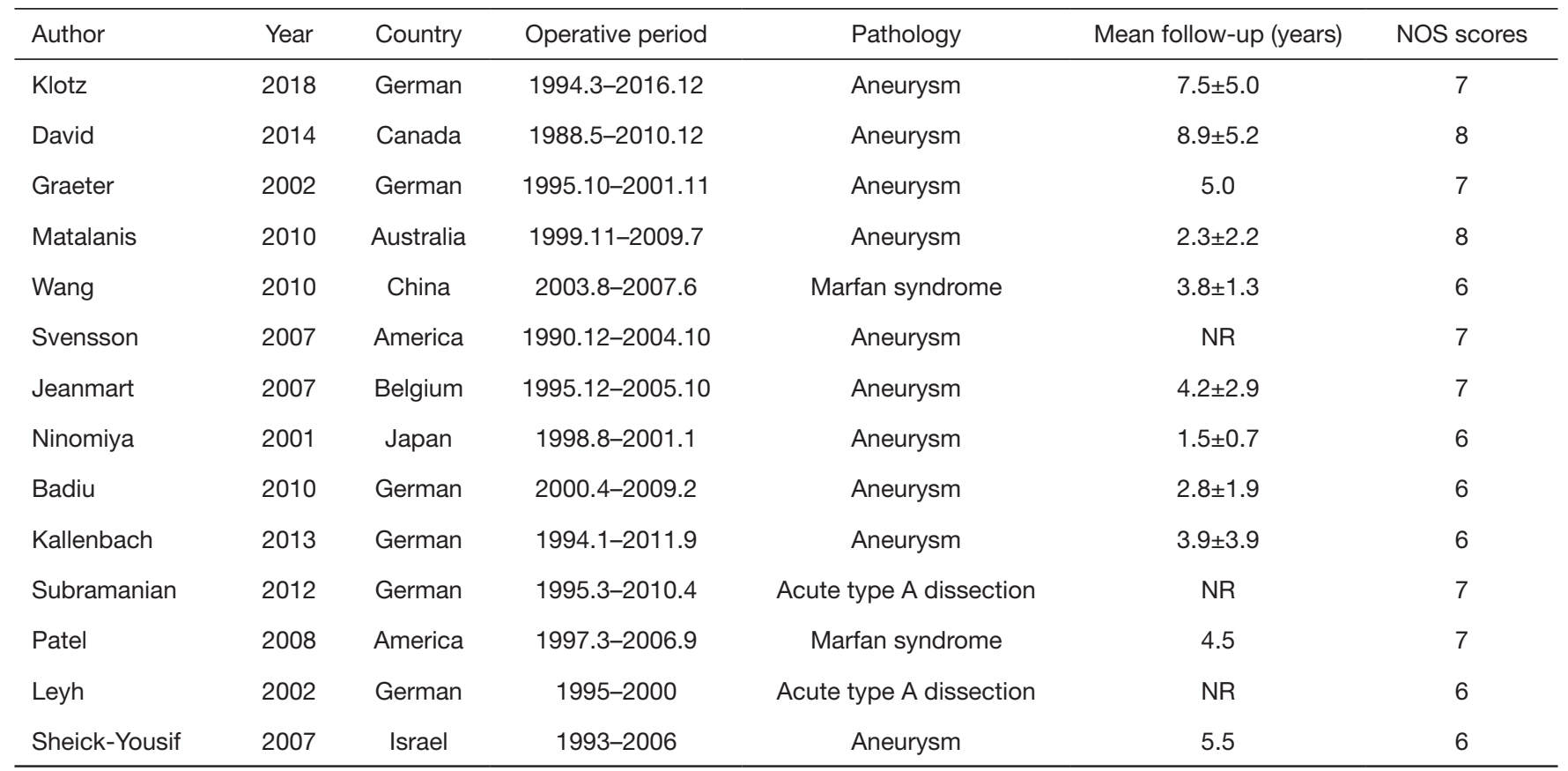

Data with \pm symbol represent mean difference and standard deviation. NOS, Newcastle-Ottawa Scale; NR, not reported. 
Table 2 Baseline characteristics of patients

\begin{tabular}{|c|c|c|c|c|c|c|c|c|c|}
\hline Author & Year & \multicolumn{4}{|c|}{ Reimplantation } & \multicolumn{3}{|c|}{ Remodeling } & Marfan (\%) \\
\hline Klotz & 2018 & 214 & $55.9 \pm 14.3$ & 83.6 & 15.4 & 101 & $48.9 \pm 14.5$ & 60.4 & 11.9 \\
\hline David & 2014 & 296 & $46.4 \pm 15.0$ & 78.0 & 36.5 & 75 & $51.5 \pm 14.6$ & 78.7 & 30.7 \\
\hline Graeter & 2002 & 21 & $47 \pm 17$ & 81.0 & NR & 98 & $62 \pm 14$ & 64.3 & NR \\
\hline Wang & 2010 & 9 & NR & NR & 100.0 & 8 & NR & NR & 100.0 \\
\hline Svensson & 2007 & 72 & 49 & 77.8 & 33.3 & 77 & 51 & 71.4 & 15.6 \\
\hline Jeanmart & 2007 & 66 & $51 \pm 15$ & 83.3 & 6.1 & 48 & $54 \pm 17$ & 68.8 & 10.4 \\
\hline Ninomiya & 2001 & 5 & $29 \pm 13$ & 20.0 & 80.0 & 3 & $46 \pm 18$ & 66.7 & 0.0 \\
\hline Subramanian & 2012 & 27 & $53 \pm 15$ & 40.7 & 7.4 & 51 & $62 \pm 14$ & 35.3 & 0.0 \\
\hline Patel & 2008 & 44 & NR & NR & 100.0 & 40 & NR & NR & 100.0 \\
\hline Leyh & 2002 & 8 & $52 \pm 15$ & NR & 25.0 & 22 & $62 \pm 16$ & NR & 4.5 \\
\hline Sheick-Yousif & 2007 & 39 & NR & NR & NR & 89 & NR & NR & NR \\
\hline
\end{tabular}

Data with \pm symbol represent mean difference and standard deviation. NR, not reported.

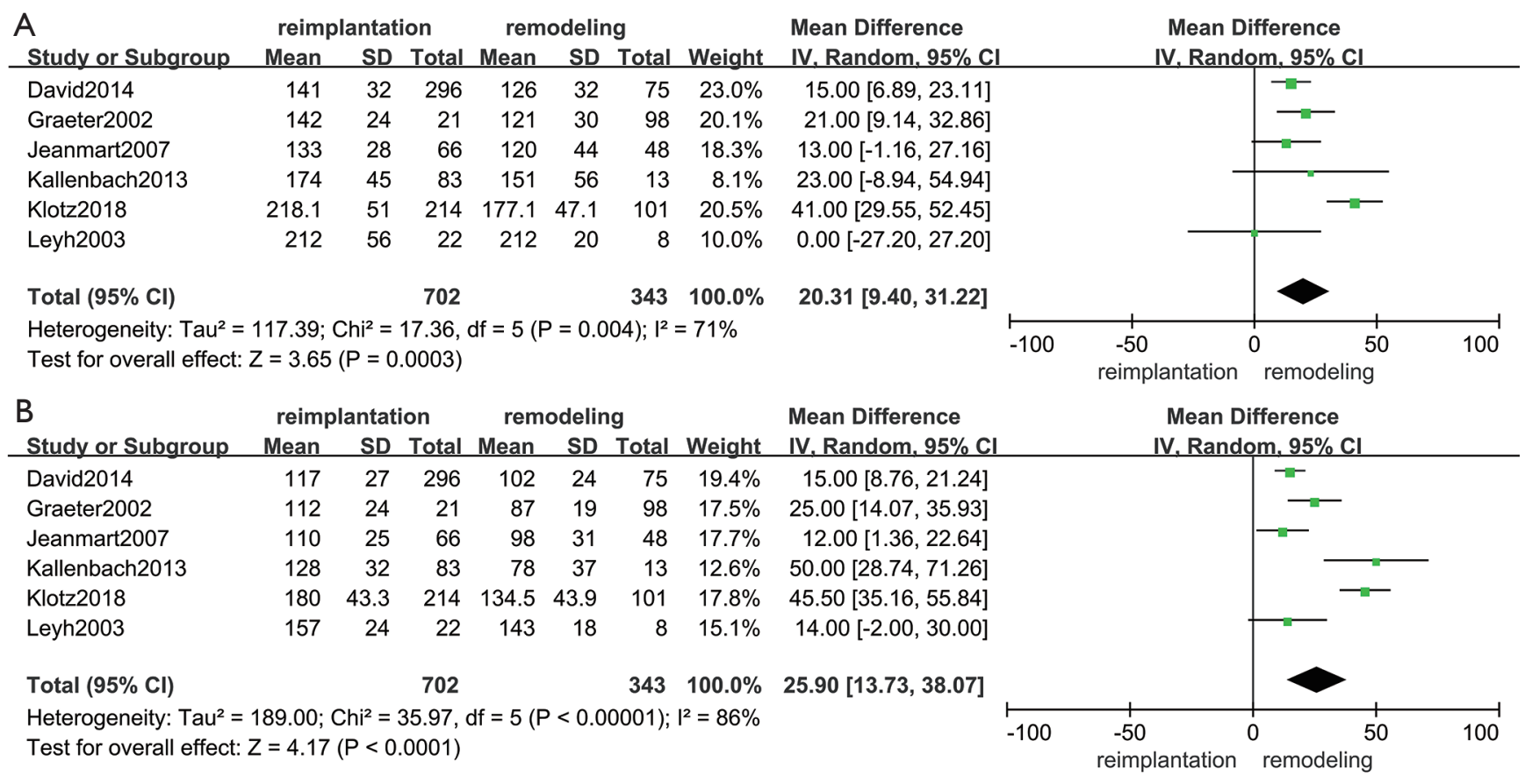

Figure 3 Forest plot showing the results of (A) cardiopulmonary bypass (CPB) time and (B) aortic clamping time with reimplantation and remodeling. SD, standard deviation; CI, confidence interval. 
test and $\mathrm{I}^{2}$ statistics indicated a high level of heterogeneity between studies in terms of both the CPB time $(\mathrm{P}=0.004$; $\left.\mathrm{I}^{2}=71 \%\right)$ and aortic clamping time $\left(\mathrm{P}<0.00001 ; \mathrm{I}^{2}=86 \%\right)$. If we excluded the klotz2017 study from the analysis of $\mathrm{CPB}$ time, then heterogeneity no longer existed $(\mathrm{P}=0.66$; $\mathrm{I}^{2}=0 \%$; random effects model, mean difference $=15.68$; 95\% CI, 9.87-21.49; $\mathrm{P}<0.00001$ ), which demonstrated that the heterogeneity came from klotz 2018 (18). However, heterogeneity consistently existed between studies in the comparison of aortic clamping time. This may result from the diversity of the surgical maneuver among different institutions.

\section{Early mortality}

Early mortality included 30-day mortality and in-hospital mortality. The results of early mortality are shown in Figure 4A. Nine studies (18,21-24,27-30) (927 patients: 528 with reimplantation and 399 with remodeling) were included in the analysis of early mortality. No evidence of heterogeneity $\left(\mathrm{P}=0.69 ; \mathrm{I}^{2}=0 \%\right)$ and no significant difference were observed in early mortality between the reimplantation group and remodeling group (random effects model, RR $=0.69 ; 95 \%$ CI, 0.31-1.53; P=0.36).

\section{Late mortality}

Late mortality was defined as mortality of patients that have been followed up for more than one year. If the studies only provided survival data $(25,27)$, we calculated the exact mortality of these studies. The results of late mortality are shown in Figure 4B. Eight studies (18,21-23,25,27,28,30,31) (725 patients: 496 with reimplantation and 229 with remodeling) were included in the analysis of late mortality. The results showed that the late mortality rate was much higher in the remodeling group than in the reimplantation group (random effects model, $\mathrm{RR}=0.34$; 95\% CI, 0.17-0.71; $\mathrm{P}=0.004)$. No evidence of heterogeneity was observed $\left(\mathrm{P}=0.18 ; \mathrm{I}^{2}=37 \%\right)$.

\section{Reoperation rate}

Reoperation included reoperations for aortic valve regurgitation, aortic valve endocarditis and aortic root abscesses during follow-up and did not include reexploration for bleeding. The results of reoperation are shown in Figure 5A. Twelve studies (18,19,21-26,28,30-32) (1,533 patients: 945 with reimplantation and 588 with remodeling) were included in the analysis of reoperation. The results showed that the reoperation rate was much higher in the remodeling group than in the reimplantation group (random effects model, $\mathrm{RR}=0.31 ; 95 \%$ CI, 0.12 0.76; $\mathrm{P}=0.01)$. However, a high level of heterogeneity was indicated between studies $\left(\mathrm{P}=0.01, \mathrm{I}^{2}=55 \%\right)$.

\section{Postoperative moderate to severe AR}

AR of grade 3 or greater was regarded as moderate to severe. We calculated the exact number of patients with postoperative moderate to severe AR when the study only provided data of freedom from moderate to severe AR (25). The results of postoperative AR are shown in Figure 5B. Eleven studies (18,19,20,22,24,25,27-30,32) (1,444 patients: 846 with reimplantation and 598 with remodeling) were included in the analysis of postoperative AR. No significant difference was shown between the two groups (random effects model, $\mathrm{RR}=0.64 ; 95 \% \mathrm{CI}, 0.31-1.32 ; \mathrm{P}=0.22)$. No evidence of heterogeneity was observed $\left(\mathrm{P}=0.12, \mathrm{I}^{2}=36 \%\right)$.

\section{Postoperative stroke}

The results of postoperative stroke are shown in Figure 6. Five studies $(18,21,24,25,29)(752$ patients: 462 with reimplantation and 290 with remodeling) were included in the analysis of postoperative stroke. No evidence of heterogeneity $\left(\mathrm{P}=0.72 ; \mathrm{I}^{2}=0 \%\right)$ and no significant difference were observed in postoperative stroke between the reimplantation group and remodeling group (random effects model, $\mathrm{RR}=1.26$; 95\% CI, 0.58-2.75; $\mathrm{P}=0.56$ ).

\section{Discussion}

Currently, high-quality evidence-based studies such as randomized control trials are unlikely to be performed in patients with aortic root aneurysms because the prevalence of this disease is relatively rare in large populations (33). However, by conducting a meta-analysis of observational studies, we can provide evidence for further surgical treatment strategies for aortic root aneurysms. The current meta-analysis was based on 14 retrospective cohort studies from 14 centers comparing reimplantation and remodeling techniques of VSARR in patients with aortic root aneurysms, which included a population of 1,672 patients from Canada, Germany, America, Belgium, Australia, China, Japan and Israel. The results of this meta-analysis indicate that patients who undergo remodeling procedures may have an almost three times higher risk of late mortality and reoperation than those who undergo reimplantation procedures. Although no significant difference was observed 


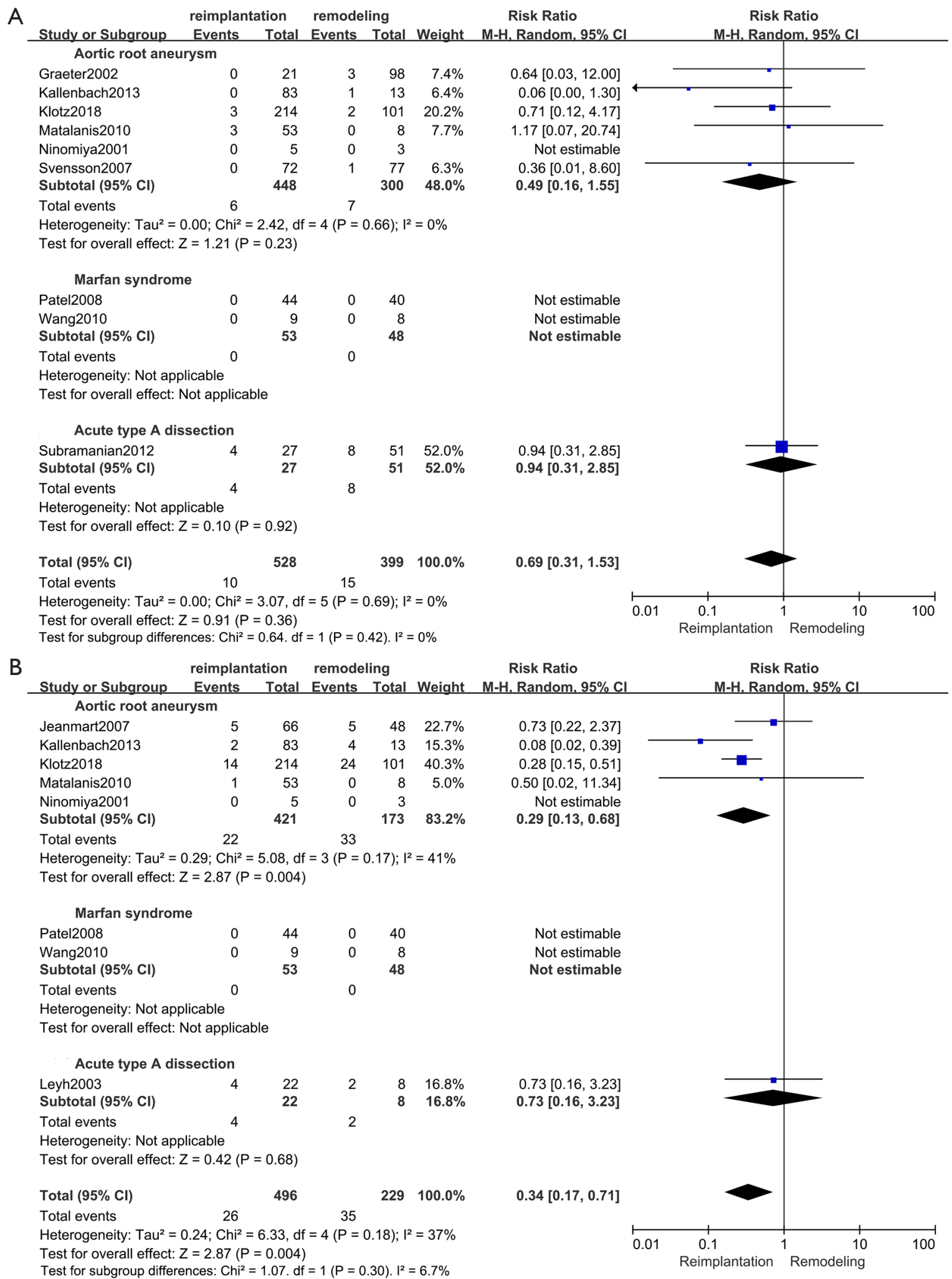

Figure 4 Forest plot showing the results of (A) early mortality and (B) late mortality with reimplantation and remodeling. MH, Mantel-Haenszel; CI, confidence interval. 


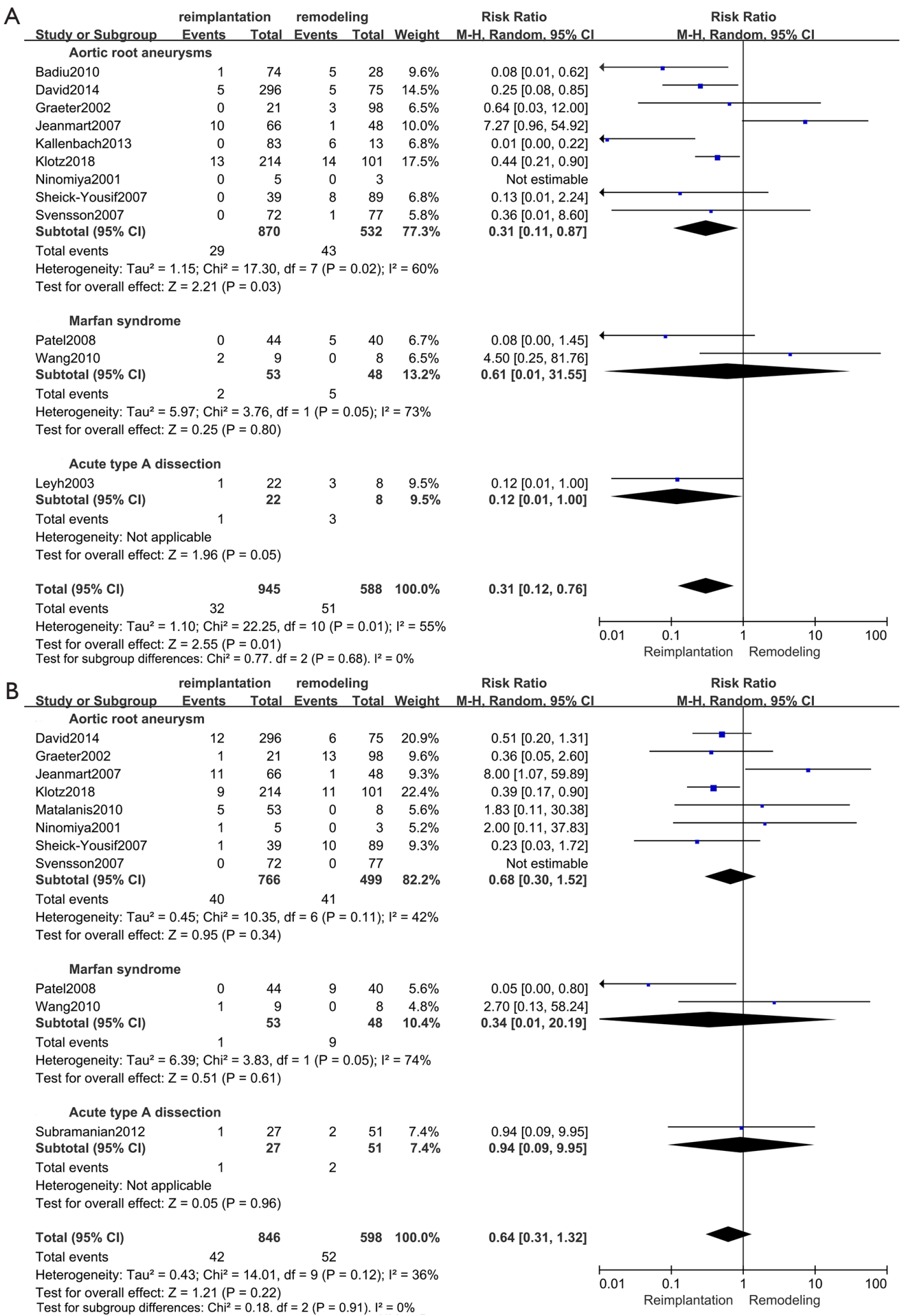

Figure 5 Forest plot showing the results of (A) reoperation, (B) postoperative moderate to severe aortic regurgitation (AR)with reimplantation and remodeling. $\mathrm{MH}$, Mantel-Haenszel; CI, confidence interval. 


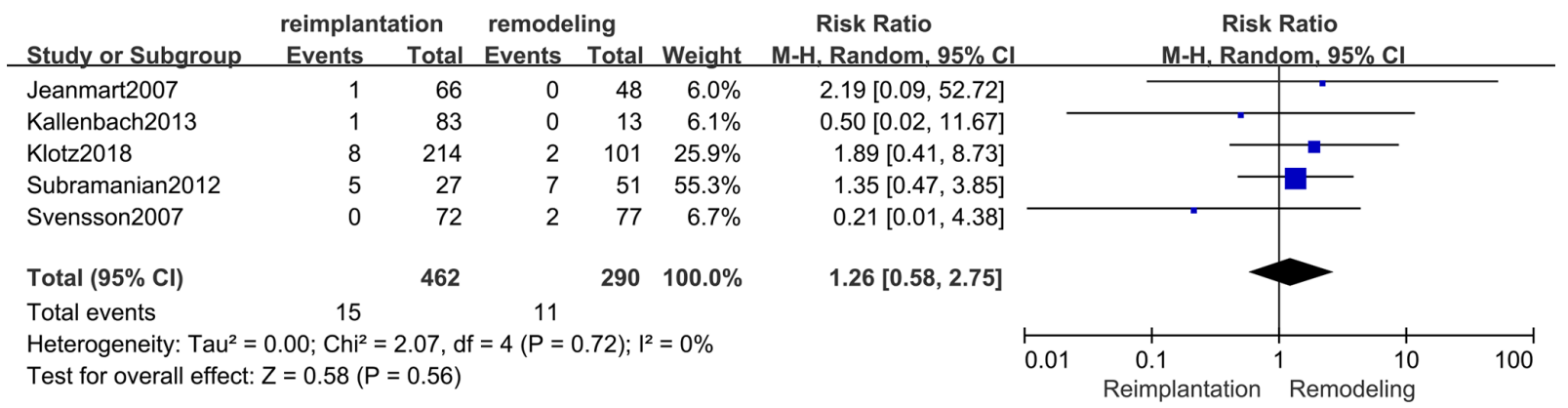

Figure 6 Forest plot showing the results of postoperative stroke with reimplantation and remodeling. MH, Mantel-Haenszel; CI, confidence interval.

in early mortality, postoperative moderate to severe AR and postoperative stroke between two groups, the trend appeared to favor reimplantation technique for early mortality and postoperative AR.

Several previously published systematic reviews and metaanalyses have compared the outcomes of reimplantation and remodeling techniques. In 2011, Liu et al. included seven studies and reported that the reimplantation technique resulted in a lower risk of reoperation related to aortic insufficiency (AI) (15). Additionally, in 2011, Rahnavardi et al. illustrated that the reimplantation technique was favored by surgeons for higher freedom from AI according to the analysis of 14 papers, but they had included several overlapping studies from the same institution (16). In 2015, Arabkhani et al. analyzed 31 studies (most of which were single-armed studies) and indicated that no significant difference was observed in the survival or reoperation rate between the reimplantation and remodeling groups (17). The conclusions drawn by these articles are important but should also be treated with caution due to the overlapping studies, the short follow-up periods and the enrollment of single-armed trials. We believe the results of the present meta-analysis are more reliable because all 14 articles comparing reimplantation and remodeling are included, and it contains several latest studies with larger sizes and longer follow-ups (18-21).

Currently, the definitions of reimplantation and remodeling techniques are not only restricted to the classic David or Yacoub procedures because modifications of these two procedures have been continuously proposed (3-5). In 2003, Dr. Craig Miller announced that all modifications of VSARR could be divided into reimplantation or remodeling groups according to whether the operation employed three aortic suture lines (reimplantation) or two (remodeling) (3).
The reimplantation technique anchors the proximal aortic valve to the ventriculo-aortic junction below the leaflets, and sutures are completed inside the tubular graft or tailored graft, which helps to reduce aortic sinus dilatation and stabilize the aortic valve, sino-tubular junction and ventriculo-aortic junction $(10,12)$. The remodeling technique relies on suturing the tailoring tubular Dacron to the remnants of the aortic sinus tissue and aortic annulus, which make it possible to preserve the native sinus of Valsalva and enable physiological movements of the valve, but there is a risk of postoperative dilation of the ventriculo-aortic junction and bleeding at the suture sites $(11,13,14)$ This may explain why a higher long-term mortality and reoperation rate occur with remodeling than with reimplantation, as shown in our results. According to previous published studies, reoperation on the ascending aorta and aortic root had a relatively higher operative mortality than primary aorta procedures and hospital mortality for reoperation varied between $6 \%$ and $19 \%$ (34-38). However, there is scarcely any articles compared the mortality for reoperation between reimplantation and remodeling, which is expected to be answered in future studies.

For the aforementioned reason, young patients with inherent genetic diseases such as Marfan syndrome, on whom dilation usually begins with the aortic sinus and expands to the sinus junction and ascending aorta, are better treated with reimplantation than with remodeling. Elderly patients with degenerative aortic aneurysms, AI and normal aortic annuli are suggested to be treated with remodeling techniques. Because in these patients, the dilation of the sino-tubular junction and aortic sinuses mostly occurs secondary to dilation of the ascending aorta, making it possible to preserve the native aortic sinus (39). Although VSARR is currently being performed by an 
increasing number of centers, the surgical indications in different institutions are inconsistent, and the selection of patients is greatly influenced by the subjective will of surgeons. Therefore, guidelines concerning the selection of candidates and techniques are warranted in the future.

Despite the advantages and pitfalls of certain techniques, the outcome greatly depends on the surgeons' experience and skill. As indicated in our results, reimplantation has a longer CPB time and aortic clamping time than remodeling, which results in longer learning curves for younger surgeons, particularly with David V operations, as they require surgeons to complete classic David surgery, constriction of the aortic annulus and sino-tubular junction, and reconstruction of the sinus of Valsalva during one operation $(34,40)$. In terms of the remodeling technique, it is easier and faster for young surgeons to master the operation, but the design of the aortic sinus is also largely based on personal experience (3).

It seemed to be paradoxical that reimplantation, which had longer CPB time and aortic clamping time, appeared to have better trend in early outcomes than remodeling. Remodeling was reported to have higher risk of operative bleeding because of the difference of suture method (41), which may explain the relatively higher early mortality. With the development of extracorporeal circulation and myocardial protection techniques, CPB time was no longer the determinant factor of mortality. Other factors like age, sex and comorbidities also influenced the early outcomes (33). However, significant difference in early mortality was not observed between two groups therefore we cannot draw the conclusion that remodeling was associated with higher early mortality. Recently, a technique combining remodeling and external ring annuloplasty was proposed and recommended as the class 1 indication for the treatment of aortic root aneurysms in the 2014 ESC guideline (42). By reconstructing the aortic root with a remodeling technique, the native aortic sinus and physiological cusp motions can be preserved when an external subvalvular aortic annuloplasty stabilizes the ventriculo-aortic junction, which combines both the advantages of remodeling and reimplantation $(43,44)$. A study in 2018 reported that the 5 -year outcomes of remodeling technique combining external ring annuloplasty were comparable with the reimplantation technique, with a survival of $100 \%$, a freedom from valverelated reoperation of $97 \% \pm 2 \%$ and a freedom from aortic insufficiency $\geq 2$ or reoperation of $84 \% \pm 5 \%$ (45). But longer follow-up times and larger sample sizes are still required before a final conclusion can be drawn.
We need to acknowledge that our study has some limitations. First, our study was based on retrospective observational cohort studies. Baseline information, selection criteria and surgical indications varied across different centers. Both the experience of surgeons and emergency surgery can affect the outcomes. Due to the nature of retrospective observational studies, it's unlikely that the all bias and heterogeneity resulted from above problems can be adjusted or eliminated. Second, the time period for patients who underwent surgeries spanned from 1988 to 2016. Although all included studies were followed up for more than one year, the difference of follow-up time between institutions can hardly be balanced, neither can we set a specified time-point (for example, 5-year follow-up) for further analysis. Additionally, the mean follow-up time for all included studies was limited to less than 10 years, and some were less than 5 years, which make it unlikely for long-term mortality and complications to be evaluated. Therefore, further investigation and longer follow-up data are warranted so that the outcomes of certain techniques can be fully assessed. Third, considering the limited information of etiology and pathology provided by included studies, we were unable to obtain etiology information from all articles and subgroup analysis could only performed within limited studies available of the outcomes of patient groups with specific etiology. The results of subgroup analysis should be interpreted with caution. Future researches with the accumulation of relevant research data and the extension of follow-up time may be able to answer the above mentioned questions more accurately.

\section{Conclusions}

In conclusion, the current meta-analysis indicates that patients who undergo reimplantation procedures have a significantly lower late mortality and reoperation rate than those who undergo remodeling procedures. However, no significant difference in early mortality, postoperative moderate to severe AR and postoperative stroke was exhibited between the two groups. Higher quality studies with larger population size and longer follow-up data are required for further analysis of VSARR outcomes.

\section{Acknowledgments}

Funding: This work was supported by National Key R\&D Program of China [grant numbers 2017YFC1105000] and the National Natural Science Foundation of China [grant 
numbers 81770319,81570039$]$.

\section{Footnote}

Reporting Checklist: The authors have completed the PRISMA reporting checklist. Available at http://dx.doi. org/10.21037/jtd-20-1407

Peer Review File: Available at http://dx.doi.org/10.21037/jtd20-1407

Conflicts of Interest: All authors have completed the ICMJE uniform disclosure form (available at http://dx.doi. org/10.21037/jtd-20-1407). The authors have no conflicts of interest to declare.

Ethical Statement: The authors are accountable for all aspects of the work in ensuring that questions related to the accuracy or integrity of any part of the work are appropriately investigated and resolved.

Open Access Statement: This is an Open Access article distributed in accordance with the Creative Commons Attribution-NonCommercial-NoDerivs 4.0 International License (CC BY-NC-ND 4.0), which permits the noncommercial replication and distribution of the article with the strict proviso that no changes or edits are made and the original work is properly cited (including links to both the formal publication through the relevant DOI and the license). See: https://creativecommons.org/licenses/by-nc-nd/4.0/.

\section{References}

1. Borst HG, Laas J. Surgical treatment of thoracic aortic aneurysms. Adv Card Surg 1993;4:47-87.

2. Gott VL, Gillinov AM, Pyeritz RE, et al. Aortic root replacement. Risk factor analysis of a seventeen-year experience with 270 patients. J Thorac Cardiovasc Surg 1995; 109:536-44; discussion 544-5.

3. Miller DC. Valve-sparing aortic root replacement in patients with the Marfan syndrome. J Thorac Cardiovasc Surg 2003;125:773-8.

4. De Paulis R, De Matteis GM, Nardi P, et al. Opening and closing characteristics of the aortic valve after valvesparing procedures using a new aortic root conduit. Ann Thorac Surg 2001;72:487-94.

5. Urbanski PP, Zhan X, Hijazi H, et al. Valve-sparing aortic root repair without down-sizing of the annulus. J Thorac
Cardiovasc Surg 2012;143:294-302.

6. Flynn CD, Tian DH, Wilson-Smith A, et al. Systematic review and meta-analysis of surgical outcomes in Marfan patients undergoing aortic root surgery by composite-valve graft or valve sparing root replacement. Ann Cardiothorac Surg 2017;6:570-81.

7. Benedetto U, Melina G, Takkenberg JJM, et al. Surgical management of aortic root disease in Marfan syndrome: A systematic review and meta-analysis. Heart 2011;97:955-8.

8. Burgstaller JM, Held U, Mosbahi S, et al. A systemic review and meta-analysis: Long-term results of the Bentall versus the David procedure in patients with Marfan syndrome. Eur J Cardiothorac Surg 2018;54:411-9.

9. Schäfers HJ. Aortic valve repair: Easy and reproducible? J Thorac Cardiovasc Surg 2015;149:129-30.

10. David TE, Feindel CM. An aortic valve-sparing operation for patients with aortic incompetence and aneurysm of the ascending aorta. J Thorac Cardiovasc Surg 1992;103:617-21.

11. Sarsam MA, Yacoub M. Remodeling of the aortic valve anulus. J Thorac Cardiovasc Surg 1993;105:435-8.

12. David TE. How i do aortic valve sparing operations to treat aortic root aneurysm. J Card Surg 2011;26:92-9.

13. Leyh RG, Schmidtke C, Sievers HH, et al. Opening and closing characteristics of the aortic valve after different types of valve-preserving surgery. Circulation 1999;100:2153-60.

14. Grande-Allen KJ, Cochran RP, Reinhall PG, et al. Recreation of sinuses is important for sparing the aortic valve: a finite element study. J Thorac Cardiovasc Surg 2000;119:753-63.

15. Liu L, Wang W, Wang $X$, et al. Reimplantation versus remodeling: A meta-analysis. J Card Surg 2011;26:82-7.

16. Rahnavardi M, Yan TD, Bannon PG, et al. Aortic valvesparing operations in aortic root aneurysms: remodeling or reimplantation? Interact Cardiovasc Thorac Surg 2011;13:189-97.

17. Arabkhani B, Mookhoek A, Di Centa I, et al. Reported outcome after valve-sparing aortic root replacement for aortic root aneurysm: A systematic review and metaanalysis. Ann Thorac Surg 2015;100:1126-31.

18. Klotz S, Stock S, Sievers HH, et al. Survival and reoperation pattern after 20 years of experience with aortic valve-sparing root replacement in patients with tricuspid and bicuspid valves. J Thorac Cardiovasc Surg 2018;155:1403-11.e1.

19. David TE, Feindel CM, David CM, et al. A quarter of a century of experience with aortic valve-sparing operations. J Thorac Cardiovasc Surg 2014;148:872-9; 
discussion 879-80.

20. Kunihara T, Aicher D, Rodionycheva S, et al. Preoperative aortic root geometry and postoperative cusp configuration primarily determine long-term outcome after valvepreserving aortic root repair. J Thorac Cardiovasc Surg 2012;143:1389-95.

21. Kallenbach K, Kojic D, Oezsoez M, et al. Treatment of ascending aortic aneurysms using different surgical techniques: A single-centre experience with 548 patients. Eur J Cardiothorac Surg 2013;44:337-45.

22. Ninomiya M, Takamoto S, Kotsuka Y, et al. Midterm results after aortic valve-sparing operation. Jpn J Thorac Cardiovasc Surg 2001;49:706-10.

23. Graeter TP, Aicher D, Langer F, et al. Mid-term results of aortic valve preservation: Remodelling vs. reimplantation. Thorac Cardiovasc Surg 2002;50:21-4.

24. Svensson LG, Deglurkar I, Ung J, et al. Aortic valve repair and root preservation by remodeling, reimplantation, and tailoring: technical aspects and early outcome. J Card Surg 2007;22:473-9.

25. Jeanmart H, de Kerchove L, Glineur D, et al. Aortic Valve Repair: The Functional Approach to Leaflet Prolapse and Valve-Sparing Surgery. Ann Thorac Surg 2007;83:S746-51; discussion S785-90.

26. Badiu CC, Eichinger W, Bleiziffer S, et al. Should root replacement with aortic valve-sparing be offered to patients with bicuspid valves or severe aortic regurgitation? Eur J Cardiothorac Surg 2010;38:515-22.

27. Matalanis G, Shi WY, Hayward PAR. Correction of leaflet prolapse extends the spectrum of patients suitable for valve-sparing aortic root replacement. Eur J Cardiothorac Surg 2010;37:1311-6.

28. Wang R, Ma WG, Tian LX, et al. Valve-sparing operation for aortic root aneurysm in patients with marfan syndrome. Thorac Cardiovasc Surg 2010;58:76-80.

29. Subramanian S, Leontyev S, Borger MA, et al. Valvesparing root reconstruction does not compromise survival in acute type a aortic dissection. Ann Thorac Surg 2012;94:1230-4.

30. Patel ND, Weiss ES, Alejo DE, et al. Aortic Root Operations for Marfan Syndrome: A Comparison of the Bentall and Valve-Sparing Procedures. Ann Thorac Surg 2008;85:2003-10; discussion 2010-1.

31. Leyh RG, Fischer S, Kallenbach K, et al. High failure rate after valve-sparing aortic root replacement using the "remodeling technique" in acute type A aortic dissection. Circulation 2002;106:I229-33.

32. Sheick-Yousif B, Shinfeld A, Tager S, et al. Aortic valve sparing surgery. Harefuah 2007;146:849-53, 910.

33. Goldfinger JZ, Halperin JL, Marin ML, et al. Thoracic aortic aneurysm and dissection. J Am Coll Cardiol 2014;64:1725-39.

34. Leshnower BG, Guyton RA, Myung RJ, et al. Expanding the indications for the David v aortic root replacement: Early results. J Thorac Cardiovasc Surg 2012;143:879-84.

35. Malvindi PG, van Putte BP, Heijmen RH, et al. Reoperations on the aortic root: experience in 46 patients. Ann Thorac Surg 2010;89:81-6.

36. Silva J, Maroto LC, Carnero M, et al. Ascending aorta and aortic root reoperations: are outcomes worse than first time surgery? Ann Thorac Surg 2010;90:555-60.

37. Luciani N, De Geest R, Anselmi A, et al. Results of reoperation on the aortic root and the ascending aorta. Ann Thorac Surg 2011;92:898-903.

38. Schepens MA, Dossche KM, Morshuis WJ. Reoperations on the ascending aorta and aortic root: pitfalls and results in 134 patients. Ann Thorac Surg 1999;68:1676-80.

39. David TE. Aortic Valve Sparing in Different Aortic Valve and Aortic Root Conditions. J Am Coll Cardiol 2016;68:654-64.

40. Rosenblum JM, Leshnower BG, Moon RC, et al. Durability and safety of David $\mathrm{V}$ valve-sparing root replacement in acute type A aortic dissection. J Thorac Cardiovasc Surg 2019;157:14-23.e1.

41. David TE, Maganti M, Armstrong S. Aortic root aneurysm: principles of repair and long-term follow-up. J Thorac Cardiovasc Surg 2010;140:S14-9; discussion S45-51.

42. Erbel R, Aboyans V, Boileau C, et al. 2014 ESC guidelines on the diagnosis and treatment of aortic diseases. Eur Heart J 2014;35:2873-926.

43. Lansac E, Di Centa I, Vojacek J, et al. Valve sparing root replacement: the remodeling technique with external ring annuloplasty. Ann Cardiothorac Surg 2013;2:117-23.

44. Youssefi P, Di Centa I, Khelil N, et al. Valve sparing root replacement: Remodeling root repair with aortic ring annuloplasty. Ann Cardiothorac Surg 2019;8:411-4.

45. Lenoir M, Maesen B, Stevens LM, et al. Reimplantation versus remodelling with ring annuloplasty: comparison of mid-term outcomes after valve-sparing aortic root replacement. Eur J Cardiothorac Surg 2018;54:48-54.

Cite this article as: Zhou Z, Liang M, Huang S, Wu Z. Reimplantation versus remodeling in valve-sparing surgery for aortic root aneurysms: a meta-analysis. J Thorac Dis 2020;12(9):4742-4753. doi: 10.21037/jtd-20-1407 